\title{
PRODUÇÃO DE TEXTOS NO TERCEIRO GRAU: UMA QUESTÃO AINDA EM PAUTA
}

\section{Lúcia de Fátima Santos ${ }^{(*)}$}

Resumo: O objetivo deste artigo é instigar o debate sobre o processo de escrita de universitários, a partir da análise de dificuldades lingüísticas e discursivas evidenciadas em produções de uma aluna do curso de Letras.

Palavras-chave: produção de textos; alunos; terceiro grau

O objeto do discurso de um locutor, seja ele qual for, não é objeto do discurso pela primeira vez neste enunciado, e este locutor não é o primeiro a falar dele. (...) Um locutor não é o Adão bíblico perante objetos virgens, ainda não designados, os quais é o primeiro a nomear (BAKHTIN, 1997, p. 319).

Essa reflexão de Bakhtin corresponde à posição que tenho procurado assumir como pesquisadora da área de Linguística Aplicada, ao (re)discutir questões vinculadas ao ensino e à aprendizagem da Língua Portuguesa, principalmente em relação a uma variedade de aspectos presentes nos textos que os alunos produzem. Esse interesse torna-se preocupação quando me deparo com produções de alunos concluintes do curso de Letras que apresentam, em geral, uma série de inadequações na articulação das idéias de um texto, mesmo depois de terem tido, no decorrer de quatro anos, o estudo sobre a Língua Portuguesa como um dos temas básicos do curso. Se esses alunos chegam ao último ano desse curso sem um domínio da escrita que lhes garanta a possibilidade de escrever um texto compreensível integralmente, parece-me razão suficiente para considerar o debate sobre a produção de textos ainda instigante, ainda em pauta, apesar de um número considerável de trabalhos já realizados nesse sentido.

(*) Doutoranda em Lingüística no Programa de Pós-Graduação em Letras e Lingüística da Universidade Federal de Alagoas (UFAL). 
Neste artigo, interessa-me analisar possíveis razões lingüísticas e discursivas que justificam algumas dificuldades evidenciadas pelos alunos nos textos que escrevem. Portanto, sem desconsiderar as condições de produção de um texto como um todo (quem disse, o que disse, a quem, de que lugar, como se disse), a análise aqui realizada focalizará, mais especificamente, como se disse. Nesse sentido, concordo com Maingueneau (1989, p.36) de que “... é preciso articular o 'como dizer' ao conjunto de fatores do ritual enunciativo. Não existe, de um lado, uma forma e, do outro, as condições de enunciação". Também acato a posição de Pêcheux (1988, p.182), ao afirmar que “... todo critério purarnente lingüístico (isto é, do tipo morfossintático) é, em sentido estrito, insuficiente para caracterizar os processos discursivos inerentes a uma formação discursiva."

Por acreditar que os sujeitos trazem à tona, nos textos que produzem, diferentes discursos que permeiam o seu dizer, considerarei textos de uma aluna em dois momentos: primeira e segunda versão. Esses textos me darão subsídios para comparar as alterações que essa aluna realizou mediante as condições de produção do momento da reescrita. Porém, antes de apresentar a análise propriamente dita, penso ser necessário tecer algumas considerações sobre a concepção de língua, de produção e de sujeito que fundamentaram a análise das produções analisadas.

De acordo com Bakhtin (1992, p.124), "a língua vive e evolui historicamente na comunicação verbal concreta, não no sistema linguístico abstrato das formas da língua nem no psiquismo individual dos falantes." Desse modo, ela tanto é determinada quanto determina os efeitos das lutas travadas nas relações sociais, sendo a palavra, nesse contexto, "fenômeno ideológico por excelência", "o modo mais puro e sensível da relação social" (id., ib., p.36). Esse caráter ideológico e histórico-social da palavra se estende ao discurso, que é a instância onde se efetiva o encontro da palavra com a realidade efetiva (Amaral, 2002, p. 25).

Bakhtin também afirma que na produção de um texto se estabelece uma relação interlocutiva, um espaço dialógico em que um sujeito se inscreve e se reinscreve na relação com o outro. Nesse sentido, ao se produzir um texto, aposta-se na "contrapalavra", na 
interlocução com um "auditório social", no "germe de uma resposta", enfim, numa compreensão ativa ${ }^{1}$. Nessa perspectiva dialógica, segundo Geraldi (1997), produzir um texto implica conceber que os sentidos são produzidos historicamente, na relação entre sujeitos. Desse modo, como já mencionei anteriormente, na construção de um texto é imprescindível atender às seguintes condições de produção: ter a quem dizer, o que dizer, razões para dizer e como dizer. Para esse autor (1997, p.136),

Na produção de discursos, o sujeito articula, aqui e agora, um ponto de vista sobre o mundo que, vinculado a uma certa formação discursiva, dela não é decorrência mecânica, seu trabalho sendo mais do que mera reprodução: se fosse apenas isso, os discursos seriam sempre idênticos, independentemente de quem e para quem resultam. Minha aposta não significa que o sujeito, para se constituir como tal, deva criar o novo. A novidade, que pode estar no reaparecimento de velhas formas e velhos conteúdos, é precisamente o fato de o sujeito comprometer-se com sua palavra e de sua articulação individual com a formação discursiva de que faz parte, mesmo quando dela não está consciente.

Essa posição de Geraldi é compatível com a de sujeito relacional, proposta por Morin (2002) e por Zozzoli (2002), que defendem a possibilidade de uma autonomia relativa para o sujeito, desde que tal autonomia se dê de forma instável, oscilante, jamais definitiva. A partir desse ponto de vista, Zozzoli (2002, p. 20-21) propõe uma ampliação da visão bakhtiniana de compreensão responsiva ativa, argumentando sobre a possibilidade de produção responsiva ativa, que corresponde à continuidade da compreensão "para além de um novo texto produzido, considerado, dessa forma, não como produto, mas como parte de um processo que se estabelece na interação verbal e não verbal, e que não se conclui na materialidade lingüística."

1 Bakhtin (1997, p. 338) estabelece uma diferença entre compreensão e explicação: esta "implica uma única consciência, um único sujeito"; aquela implica "duas consciências, dois sujeitos". 
Nessa perspectiva, as considerações que serão feitas sobre os aspectos lingüísticos e discursivos das produções aqui analisadas correspondem, na escrita, à posição que Bakhtin (1997, p. 326) assume sobre a fala, ao afirmar que os

[...] recursos especializados da língua (recursos gramaticais) jamais abrangem, claro, todas as expressões pelas quais a fala se dirige a um destinatário. Certos recursos linguíísticos podem até estar completamente ausentes; ainda assim o enunciado refletirá, com grande agudeza a influência do destinatário de sua presumida reação-resposta. É sob uma maior ou menor influência do destinatário e de sua presumida resposta que o locutor seleciona todos os recursos lingüísticos de que necessita. (grifo do autor)

Ao produzir um texto escrito, o sujeito-autor também procede de modo semelhante, porque as escolhas das idéias, das palavras, do gênero, enfim de todos os aspectos envolvidos na produção de um texto, estão intrinsecamente interligados à imagem que ele faz do sujeito-leitor no processo de produção. Se isso acontece no processo de escrita da primeira versão do texto, é possível que na reescrita ${ }^{2}$ essa reflexão aconteça de modo mais efetivo, porque ela propicia a troca de papéis, uma outra leitura, a construção de novos sentidos. Como afirma ainda Bakhtin (1997, p.332), "a reprodução de um texto pelo sujeito (volta ao texto, releitura, nova execução, citação) é um acontecimento novo, irreproduzível na vida do texto, é um elo na cadeia histórica da comunicação verbal".

Um olhar sobre os dados

A análise dos dados será baseada em duas versões de uma resenha ${ }^{3}$ de uma aluna do primeiro ano, produzidas em um contexto

2 Vale conferir as reflexões de ABAURRE, FIAD; MAYRINKSABINSON (1997) sobre o processo de reescrita.

3 Os textos analisados fazem parte do corpus do projeto de pesquisa Leitura e produção de textos na sala de aula de línguas: a constituição de uma gramática do aluno, do qual participei no período de 1997 a 2002, sob a coordenação geral da Profa. Rita Zozzoli. 
de intervenção, ${ }^{4}$ no qual a professora assumiu a condição de pesquisadora. Tanto a escrita quanto a reescrita foram produzidas no início do ano letivo de 1998. A produção da primeira versão foi norteada pela leitura de textos ${ }^{5}$ no decorrer das aulas da disciplina Língua Portuguesa 1. Como já disse anteriormente, considerei importante selecionar um texto que foi reescrito, porque isso possibilitaria observar os processos discursivos ${ }^{6}$ realizados e os sentidos produzidos depois dos comentários da professora e da turma. ${ }^{7}$

Nos comentários sobre a primeira versão, a professora retomou as reflexões dos aspectos inerentes a uma resenha e enfatizou a necessidade de os alunos apresentarem as idéias dos textos resenhados com mais clareza, para que os leitores pudessem constituir sem dificuldades um possível sentido. Para isso discutiu com a turma diferentes inadequações dos textos, e, à medida que professora e alunos apontavam aspectos incompreensíveis nas resenhas, eram discutidas propostas de reelaboração.

4 Segundo THIOLLENT (2000, p.8), alguns pesquisadores chamam pesquisa-ação, outros pesquisa participante. Entenda-se aqui intervenção de acordo com o que propõe ZOZZOLI (2002, p.22): "etapa de investigação em que são introduzidas propostas de ação a partir de observações já efetuadas em contextos semelhantes." Essa é uma prática de pesquisa muito freqüente na área de Lingüística Aplicada. No caso em questão, a turma foi observada durante um ano letivo. Todas as aulas foram gravadas em áudio e foram realizados registros em notas de campo. A produção foi baseada na leitura e discussão dos textos "A gente é o que mesmo?," de Mário Prata, e "Os novos pobres", de Frei Beto. Ambos os autores tecem comentários críticos sobre as denominações atribuídas ao Brasil nas últimas décadas: país subdesenvolvido, em desenvolvimento, emergente etc. O primeiro texto, publicado na revista Istoé, em 10/06/98; e o segundo, no jornal Folha de S. Paulo, em 19/07/98.

6 De acordo com Pêcheux (1988, p.161), processo discursivo é "o sistema de relações de substituição, paráfrases, sinonímia, etc, que funcionam entre elementos lingüísticos - 'significantes'- em uma formação discursiva dada."

7 A professora fez comentários por escrito nos textos de todos os alunos da turma, selecionou trechos de algumas produções para discutir nas aulas e depois sugeriu a reescrita. 
Além das produções, a análise foi subsidiada por dados obtidos em notas de campo e transcrições das aulas observadas.

Primeira versão do texto ${ }^{8}$

Os textos de Mario Prata e Frei Beto esboça-se no quadro sócio-econômico brasileiro, nos quais, mostram em que situação se encontra o pobre do Brasil.

A questão da crise no Brasil não é de agora. Mário Prata volta ao passado quando diz no texto que, já pequeno, o seu pai falava que o país era pobre, mas o mesmo já dizia: Esta situação vai mudar. Mario Prata no decorrer do texto vai traçando o pérfil de cada década, de cada acontecimento, de como o Brasil mudou de nomes, como: subsenvolvido, terceiro mundo, desenvolvido e por último, país emergente

E faz uma ressalva, de que, (O G-7 + Rússia, continua o mesmo, cada vez mais rico, citado no texto estas frases, continuando. (e o Brasil cada vez mais pobre). E pergunta ao leitor. (Como será conhecido o Brasil no novo milênio?)

No texto de Frei Betto, ele se aprofunda mais com relação ao problema do pobre brasileiro.

Mais uma classe que surgiu, são: Os novos pobres ou imergentes, (funcionários públicos desempregados, empresários falidos e aposentados).

Como ele cita no texto, (São diferentes das camadas pobres da sociedade, integradas por quem vive na pobreza dinástica, a que passa de geração em geração).

Fala sobre as condições em que o FMI, impôs ao Brasil e que os novos pobres não tem ace-sso à casa própria, educação e a saúde. E que os jovens logo após os estudos não sabe a carreira que vai seguir.

Como foi citado no início do texto, os dois autores tratam do mesmo assunto, apesar da na-rrativa ser diferente.

Chega-se a conclusão de que no Brasil só modifica-se a linguagem, porque a sociedade e o governo é o mesmo. 
Se for feita a leitura desse texto com o intuito de se fazer apenas um julgamento das questões lingüísticas, é possível apontar uma série de inadequações desde um nível microlingüístico, como a separação de sílabas (ace-sso, na-rrativa), até um nível macrolinguiístico, como a organização das idéias na constituição de um parágrafo ( $E$ faz uma ressalva, de que, $(O G-7+R u ́ s s i a$, continua o mesmo, cada vez mais rico, citado no texto estas frases, continuando. (e o Brasil cada vez mais pobre). E pergunta ao leitor. (Como será conhecido o Brasil no novo milênio?). Entretanto, como já disse anteriormente, esse não é o meu objetivo. Assim, tais construções serão analisadas sempre atreladas às condições de produção de um modo geral.

Levando-se em consideração a visão dialógica de Bakhtin, fica difícil o leitor interagir com algumas das idéias dessa primeira versão, principalmente se ele desconhecer os textos resenhados. Essa dificuldade se deve à forma como tais idéias foram apresentadas. A aluna demonstra conhecer algumas das estratégias exigidas na construção de uma resenha, porém não sabe como articulá-las para que possa estabelecer a interlocução com seus prováveis leitores. Aqui, no caso, a professora da disciplina e os colegas de turma ${ }^{9}$.

Logo na introdução do texto, ficam evidentes as marcas de heterogeneidade ${ }^{10}$ peculiares a uma resenha, como a referência

9 Desde o início do ano, os alunos tinham conhecimento de que os textos produzidos por eles poderiam ser objeto de análise durante as aulas. Para evitar qualquer tipo de constrangimento, já que essa era uma prática completamente nova para eles, a professora tinha o cuidado de digitar os textos e de omitir qualquer dado de identificação, antes de apresentá-los à turma.

10 Segundo MAINGUENEAU (1989, p.75), falar sobre heterogeneidade do discurso significa "tomar conhecimento de um funcionamento que representa uma relação radical de seu "interior" com seu "exterior". Lembrando a distinção proposta por AUTHIER-REVUZ (1982): heterogeneidade mostrada e heterogeneidade constitutiva, Maingueneau afirma que a primeira "incide sobre as manifestações explícitas, recuperáveis a partir de uma diversidade de fontes de enunciação", e a segunda "aborda uma heterogeneidade que não é marcada em superfície, mas que a AD pode definir, formulando hipóteses, através do interdiscurso, a propósito da constituição de uma formação discursiva". 
explícita aos textos de Mário Prata e Frei Beto. E, no decorrer da resenha, há indícios das orientações do discurso escolar acerca da construção desse gênero discursivo, como: na tentativa de iniciar o texto com uma síntese das idéias básicas dos textos comentados; no cumprimento das etapas de constituição de um texto: início, meio e fim; na tentativa de mostrar um caráter de impessoalidade na apresentação das idéias dos textos comentados. Em relação a essa última "recomendação", Bakhtin (1997, p.283) afirma que textos que pertencem ao gênero científico (como é o caso em questão) são menos favoráveis à expressão da individualidade por requererem uma forma padronizada. A aluna demonstra ficar muito presa a esse padrão do discurso científico ao apresentar as idéias dos autores de forma muito colada. Até mesmo quando é aberto um espaço para uma reflexão crítica - como eın geral é feito na conclusão de uma resenha - a aluna não se desprende da paráfrase, como vemos em:

F1 ${ }^{11}$ Chega-se a conclusão de que no Brasil só modifica-se a linguagem, porque a sociedade e o governo é o mesmo.

Nesse fragmento, a imparcialidade é marcada pela forma indeterminada, impessoal, como ela inicia o enunciado: Chega-se. Porém atribuo essa tentativa de distanciamento não só à possibilidade de ela procurar apresentar um texto de acordo com o padrão científico (cumprindo supostamente orientações da professora), mas,
principalmente, à dificuldade de ela se apropriar das idéias de Mário
Prata e de Frei Beto Prata e de Frei Beto sem reproduzi-las totalmente. E, o mais aqueles possíveis dos textos desses autores. É provável que essa seja a razão por que ela apresenta afirmações vagas, como em F1, e também
nos fragmentos a seguir:

F2 Mário Prata volta ao passado quando diz no texto que, já
pequeno, o seu pai falava que o país dizia: Esta seu pai falava que o país era pobre, mas o mesmo já vai traçando o pérfil de cada década Prata no decorrer do texto como o Brasil mudou de nomes, como: subsenvolvido, terceiro mundo, desenvolvido e por último, país emergente.

F3 E faz uma ressalva, de que, (O G-7 + Rússia, continua o mesmo, cada vez mais rico, citado no texto estas frases,

$11 \quad F=$ fragmento 
UMA QUESTÃO AINDA EM PAUTA

continuando. (e o Brasil cada vez mais pobre). E pergunta ao leitor. (Como será conhecido o Brasil no novo milênio?)

F4 Como ele cita no texto, (São diferentes das camadas pobres da sociedade, integradas por quem vive na pobreza dinástica, a que passa de geração em geração).

F5 Como foi citado no início do texto, os dois autores tratam do mesmo assunto, apesar da na-rrativa ser diferente.

Nesses fragmentos, a incompletude ou vaguidão dos enunciados, a cópia de trechos dos textos resenhados e o uso de expressões introdutórias de uma forma excessiva e confusa (como estão destacadas nos fragmentos $2,3,4,5$ ) são evidências de que a aluna ainda não tem o domínio das estratégias de construção de uma resenha, nem do ponto de vista lingüístico nem discursivo. Por exemplo, em F3 ela usa inadequadamente os parênteses para sinalizar para o leitor que são idéias dos textos comentados. Essa inadequação do uso dos parênteses torna mais difícil a constituição de sentido quando se observa que não acontece de modo uniforme: ora a aluna faz uma cópia (São diferentes das camadas pobres da sociedade, integradas por quem vive na pobreza dinástica, a que passa de geração em geração), ora faz uma paráfrase (Como será conhecido o Brasil no novo milênio?)

Embora o texto seja marcado predominantemente pela reprodução das idéias dos textos comentados, há indício de gestos de interpretação, como na paráfrase Como será conhecido o Brasil no novo milênio? No texto de Mário Prata a pergunta é a seguinte: $E$ como é que vão chamar a gente na próxima década, que já será no novo século? Embora a aluna utilize a forma de discurso direto, ela não faz uma cópia do texto de Mário Prata. Além disso, ela estabelece uma posição de distanciamento ao trocar a expressão a gente pela expressão o Brasil.

Considerando a posição de Maingueneau (1989, p.88) de que toda interpretação de uma citação é afetada de acordo com a função do verbo escolhido para introduzir o discurso relatado, há também gestos de interpretação na escolha das sequiências introdutórias usadas pela aluna. Apesar de ela ter usado basicamente os verbos dizer, citar, aparentemente neutros, há indícios de um gesto de interpretação no fragmento 2 ( faz uma ressalva), pois acredito que fazer uma ressalva pressupõe assumir uma posição em relação a um fato sobre o qual se 
tem uma opinião formada, uma reflexão elaborada, não corresponde a fazer meramente uma citação. É provável que a aluna tenha interpretado as reflexões de Mario Prata como a fala de alguém comprometido com as questões histórico-sociais e econômicas do Brasil.

Segunda versão do texto

O autor Mário Prata, com o texto, "A gente é o que mesmo?, mostra a situação financeira do Brasil no decorrer da década de 50 à 90, rumo a caminho do milênio.

Claro, com uma pitada de ironia ele narra a façanha do Brasil de passar por várias fases econômicas como: O Brasil deixou de ser um país pobre, Agora o Brasil era um país subdesenvolvido!, Agora sim, a gente era um país do terceiro Mundo e depois estavamos emergentes

E no final, ele faz um comentário sobre o G-7 que cada vez fica mais rico, e agente só muda de nome. Eles primeiro mundo, e nós? Como vão chamar a gente na próxima década? Perguntou ele.

Frei Betto comenta em seu texto, que os novos pobres são os desempregados, funcionários públicos aposentados e empresários falidos que diante do novo fenômeno que surgiu, que é a era da globalização e o neoliberalismo.

Como ele mesmo diz não são os das favelas; mas, os que sobrevivem no vermelho e que recebem ajuda dos familiares. comparando o texto de Mário Prata e Frei Betto, há uma ligação.

O que afeta o Brasil lá fora é óbvio afeta também agente aqui. enquanto o Brasil está tentando estabilizar a situação lá fora, aqui vai surgindo os novos pobres que são os imergentes. e lá fora o Brasil vai mudando de nome, nós vamos também mudando.

$\mathrm{O}$ autor Frei Betto poderia perguntar ao leitor como o autor Mário Prata perguntou, como são chamados os novos pobres no novo século?

Assim como Bakhtin (1997, p.332), concebo a reescrita de um texto como um "elo na cadeia histórica da comunicação verbal," que oferece a oportunidade de haver a alternância de papéis. Ao fazer comentários no texto da aluna, a professora assume o papel de coautora. A aluna, por sua vez, ao ler os comentários da professora, passa a ocupar o lugar de leitora, manifestando uma atitude responsiva 
de aceitação ou negação acerca dos elos dessa cadeia, e retorna ao lugar de produtora quando acata a sugestão de reescrever a primeira versão do texto.

Logo na introdução da segunda versão, há indícios desse diálogo não só com a professora, mas também com os colegas da turma, já que as resenhas foram discutidas em sala de aula. Nesta versão, a aluna apresenta o autor, o título do texto resenhado, como também procura dizer com mais clareza o que acredita ser a idéia central do texto. Essas alterações, muito provavelmente, são fruto das reflexões sobre a primeira versão, porque, na aula em que as resenhas foram discutidas, a professora enfatizou a necessidade de os alunos dizerem na resenha que texto especificamente de cada autor estava sendo comentado e o que havia de comum entre as idéias desenvolvidas nos dois textos. Também na primeira versão a professora marcou o trecho que tornava incompreensível a introdução: esboça-se no quadro sócio-econômico brasileiro, nos quais mostram em que situação se encontra o pobre Brasil. Porém essas orientações da professora são seguidas parcialmente pela aluna. Ainda na introdução, ela demonstra negar as orientações da professora, quando abandona a tentativa de reunir as idéias dos dois textos em um só parágrafo, como fez na versão anterior, optando por fazer uma apresentação das idéias de cada texto separadamente. Entretanto essa opção poderá causar problemas de compreensão, principalmente para o leitor que desconhece as condições de produção da resenha, porque ele não compreenderá a passagem da discussão das idéias do texto de Mario Prata para o texto de Frei Beto.

Após tecer considerações sobre o texto de Mario Prata $\left(1^{\circ}\right.$ a $3^{\circ}$ parágrafos), a aluna apresenta as idéias do texto de Frei Beto. Como não é proposto nenhum elo na passagem da apresentação das idéias de um autor (no caso, Mario Prata) para o outro (Frei Beto), há uma ruptura entre o terceiro e quarto parágrafos. Essa ruptura parece não ser percebida pela aluna, pois no quinto parágrafo ela faz uma comparação vaga entre os textos dos autores (comparando o texto de Mário Prata e Frei Betto, há uma ligação) como se já tivesse estabelecido um contraponto entre esses textos. Isso se justifica porque ela adota uma comparação da primeira versão (Como foi citado no início do texto, os dois autores tratam do mesmo assunto, apesar da narrativa ser diferente) sem perceber a 
alteração na constituição de sentidos. Na primeira versão, mesmo de uma forma vaga e confusa, ela havia explicitado o contraponto entre os autores desde a introdução, de modo que foi possível retomar esse contraponto no penúltimo parágrafo, quando afirma Como foi citado no início do texto, os dois autores tratam do mesmo assunto; mas na segunda versão, conforme já disse anteriormente, o elo entre as idéias de Mario Prata e Frei Beto não está explícito.

É possível que, na segunda versão, a aluna não tenha apresentado explicitamente o contraponto entre as idéias dos textos resenhados por entender a primeira versão como parte constitutiva da segunda. Como esse contraponto já havia sido apresentado na primeira versão, ela comete o "deslize" de omiti-lo na segunda versão, provavelmente porque o elo entre os autores estivesse muito claro para ela. Essa possibilidade parece se confirmar quando se considera a possibilidade de a aluna ter previsto, no processo de reelaboração da resenha, como interlocutores apenas a professora e os colegas, que conheciam as condições de produção e, por isso, teriam condições de distinguir as idéias de Mário Prata das de Frei Beto. Essa reflexão, entretanto, não invalida o cuidado que todo produtor deve ter com a organização formal dos enunciados, a fim de apresentar pistas que facilitem a compreensão do leitor. Como lembra Geraldi (1997:10), a construção de sentidos no processo interlocutivo depende também do uso de recursos expressivos "e não só de supostas intenções que o interlocutor atribua ao locutor."

Ainda nessa segunda versão da resenha, valem ser observadas outras alterações, que muito provavelmente são indícios das vozes que permearam o processo de reelaboração, como o modo de citação das idéias de Mário Prata e de Frei Beto. Na versão anterior, a aluna usou de forma equivocada os parênteses para marcar algumas citações; nessa segunda versão, todos os parênteses foram retirados, e ela passou a fazer a cópia de idéias dos textos resenhados sem marcar com aspas. A ausência das aspas não permite o leitor distinguir a paráfrase da cópia, como em:

F6: Claro, com uma pitada de ironia ele narra a façanha do Brasil de passar por várias fases econômicas como: O Brasil deixou de ser um país pobre, Agora o Brasil era um país subdesenvolvido!, Agora sim, a gente era um país do terceiro Mundo e depois estavamos emergentes. 
Os trechos assinalados em F6 são cópias das idéias do texto de Mario Prata, que se encontram no segundo, terceiro e quinto parágrafos, respectivamente. Porém o leitor que desconhece o texto provavelmente não desconfiará que esses trechos são cópias, porque a forma despojada do uso de expressões, como claro, pitada de ironia, a façanha, usadas na introdução do parágrafo; a marca de entusiasmo do ponto de exclamação na construção Agora o Brasil era um país subdesenvolvido! e o uso da expressão Agora sim apontam para possíveis gestos de interpretação, porém isso não ocorreu.

Outra marca do texto que poderia levar o leitor a constituir um sentido de que seria uma negação à objetividade do discurso científico, um possível compromisso da aluna com as idéias apresentadas, é a presença de marcas da primeira pessoa do plural (nós/ a gente), como se confirma em:

F7: Eles primeiro mundo, e nós?

F8: O que afeta o Brasil lá fora é óbvio afeta agente aqui.

F9: Nós vamos também mudando

Porém o uso da primeira pessoa do plural, na segunda versão da resenha, evidencia que a aluna procurou imitar uma estratégia de escrita do texto de Mario Prata. Esse autor usa repetitivamente as formas a gente e nós no decorrer de seu texto. Para finalizar a reflexão sobre essa segunda versão da resenha, vale discutir a reelaboração do terceiro parágrafo, que foi o mais confuso na primeira versão. Nesta versão, ficou bem mais compreensível.Vejamos então as diferenças através do confronto entre as duas versões:

Primeira versão

F10 E faz uma ressalva, de que, (O G-7 + Rússia, continua o mesmo, cada vez mais rico, citado no texto estas frases, continuando. (e o Brasil cada vez mais pobre). E pergunta ao leitor. (Como será conhecido o Brasil no novo milênio?)

Segunda versão

F10 E no final, ele faz um comentário sobre o G-7 que cada vez fica mais rico, e agente só muda de nome. Eles primeiro mundo, e nós? Como vão chamar a gente na próxima década? Perguntou ele. 
Na segunda versão, a aluna resolve a dificuldade que teve de introduzir o discurso relatado na primeira versão (citado no texto estas frases, continuando), evitando fazer uma cópia dos enunciados do texto, optando pela paráfrase. Nessa alteração, ela faz uma substituição do enunciado e o Brasil cada vez mais pobre por e agente só muda de nome. Essa substituição dificultou a constituição de sentido porque ela coloca em posição de adversidade duas idéias que não se correspondem semanticamente: $o G-7$ que cada vez fica mais rico, e agente só muda de nome. Possivelmente, um leitor que desconhece o texto comentado não associará facilmente mudar de nome a ficar cada vez mais pobre.

Em F10, também vale mencionar a alteração do substantivo comentário pelo substantivo ressalva. Como já foi dito anteriormente, fazer uma ressalva pressupõe um compromisso maior com o que se diz do que fazer um comentário. É possível que essa substituição seja conseqüência de uma outra posição assumida pela aluna na releitura do texto de Mario Prata.

\section{Considerações finais}

Retomando a metáfora do Adão bíblico proposta por Bakhtin, tenho a clareza de que as considerações levantadas aqui sobre os textos analisados não constituem $A$ análise, mas UMA análise entre tantas outras que poderão ser realizadas na cadeia ininterrupta da interação verbal. Nesse sentido, os textos analisados se, por um lado, ratificam as representações que um grande número de autores têm apresentado sobre a produção de textos na escola; por outro lado, dão indicações de que a mudança dessas representações deve ter como ponto de partida e de chegada a realidade da sala de aula ${ }^{12}$, tendo como protagonistas professores e alunos. Daí a minha crença nos trabalhos de pesquisa de intervenção que defendem a sala de aula como um espaço em que os sujeitos possam, parafraseando Certeau

12 Essa posição não significa acreditar que na sala de aula se resolvam todos os problemas relacionados ao ensino e à aprendizagem, mas tem o intuito de marcar uma oposição aos trabalhos de pesquisa que discutem as questōes de ensino e aprendizagem de uma forma distanciada do que realmente acontece dentro da sala de aula e vêem a intervenção como aplicação de teorias. 
(2002, p.38), inventar e reinventar o cotidiano com milhares de formas de caça não autorizada, assumindo de fato uma posição responsivaativa (Bakhtin , 1992, p.1997) frente aos discursos cristalizados, como o de que escrever bem é construir um texto de acordo com as regras estabelecidas nos manuais didáticos, de preferência utilizando palavras incomuns e construções pouco usuais para denotar erudição. Esse é um discurso, entre tantos outros semelhantes, privilegiado nas práticas escolares do ensino básico, enfatizado na indústria de macetes dos cursinhos pré-vestibulares e, lamentavelmente, muitas vezes, repetido nas salas de aula das universidades.

Na memória da história de escrita da aluna que produziu os textos aqui analisados, devem existir muitos desses discursos cristalizados. Isso talvez justifique algumas das dificuldades apresentadas por ela nas duas versões dos textos, porém é válido mencionar o desejo que ela demonstra de sair desse circuito de mera consumidora de fórmulas e modelos pré-estabelecidos, quando não se nega a reconstruir o texto, procurando inserir mudanças, tentando, enfim, assumir uma outra forma de dizer.

Referências

ABAURRE, Maria Bernadete M, FIAD; Raquel S.; MAYRINKSABINSON. Cenas de aquisição da escrita: o sujeito e o trabalho com o texto. Campinas: ALB:Mercado de Letras, 1997.

AMARAL, Maria Virgínia Borges. Abram aspas! O outro quer falar. In: ZOZZOLI, Rita (Org.). Ler e produzir: discurso, texto e formação do sujeito leitor/produtos. Maceió:EDUFAL, 2002a, p. 148-165.

AMARAL, Maria Virgínia Borges. Análise do Discurso: Língua, Historia e Ideologia. In: MAGALHÃES, Belmira; AMARAL, Maria Virgínia B. (Orgs.). Leitura-Análise do Discurso. PPGL/UFAL, n 23. Maceió:EDUFAL, p. 25-46, 2002 b.

BAKHTIN, M. Marxismo e filosofia da linguagem. Tradução de Michel Lahud e Yara F. Vieira. São Paulo, Hucitec, 1992.

BAKHTIN, M. Estética da criação verbal. Tradução de Maria Emantina Galvão G. Pereira. São Paulo: Martins Fontes, 1997. 
CERTEAU, Michel. A invenção do cotidiano: artes de fazer. Tradução de Ephraim Ferreira Alves. Petrópolis: Vozes, 1996.

GERALDI, João W. Portos de Passagem. 4 ed. São Paulo: Martins Fontes, 1997.

MAINGUENEAU, Dominique. Novas tendências em Análise do Discurso. Tradução de Freda Indursky. São Paulo: Pontes, 1989.

PÊCHEUX, Michel.. Semântica e discurso. Tradução de Eni Orlandi et all. Campinas: Ed. da Unicamp, 1988.

ZOZZOLI, Rita Maria D. Compreensão e produção ativas: indícios nas produções dos alunos. In ZOZZOLI, Rita (Org.). Ler e produzir: discurso, texto e formação do sujeito leitor/produtos. Maceió:EDUFAL, 2002, p. 17-45. 